\title{
Hemimandibulectomy of mandibular large odontogenic myxofibroma in adolescence girl and immediate reconstruction with $\mathrm{AO}$ plate
}

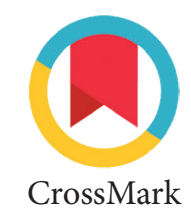

Victor T. Pamolango, ${ }^{1 *}$ Agus Nurwiadh, ${ }^{1}$ Melita Sylvyana, ${ }^{2}$ Alwin Kasim ${ }^{1}$

\section{Abstract}

Objective: Odontogenic myxofibroma is a rare, benign, but locally aggressive neoplasm found exclusively in the jaws. It has a predilection to occurs in the 2nd-3rd decade. The lesion often grows without symptoms and presents as a painless swelling. Most common clinical variant is associated with the impacted tooth and shows local invasion. Methods: A 15-year-old girl with a slow growing, painless swelling in the left mandibular region since 2 years. A radiological examination revealed a multilocular radiolucency extending from first molar up to coronoid process with impacted 3rd molar. Biopsy was done and the histopathological examination showed a myxofibroma.
Hemimandibulectomy was done and the tumor mass was resected along with it. Then the mandibular was reconstructed with A0 plate. Results: In this case hemimandibulectomy was done due to high rate of recurrence, surgical treatment through bone resection is the most indicated treatment modality and the patient must be followed-up closely for years.

Conclusion: A0 Plate for mandibularreconstruction was considered because it was safe, rapid, easy and tissue tolerance is good. The neoplasm diagnosed on the basis of radiographic imaging modalities and histopathological examination.
'Department of Oral \& Maxillofacial Surgery, Faculty of Dentistry, Padjadjaran University, Bandung, Indonesia

${ }^{2}$ Department of Oral \& Maxillofacial Surgery, Hasan Sadikin General Hospital, Bandung, Indonesia

*Correspondence to: Victor Tengar Pamolango, Department of Oral \& Maxillofacial Surgery, Faculty of Dentistry, Padjadjaran University victorshego@yahoo.co.id

Received: 04 April 2016 Revised: 15 November 2016 Accepted: 22 November 2016 Available Online: 18 December 2016

Keywords: A0 Plate, Bone resection, Hemimandibulectomy

Cite this Article: Pamolango VT, Nurwiadh A, Sylvyana M, Kasim A. 2016. Hemimandibulectomy of mandibular large odontogenic myxofibroma in adolescence girl and immediate reconstruction with A0 plate. Journal of Dentomaxillofacial Science 1(3): 206-209. D0I:10.15562/ jdmfs.v1i3.319

\section{Introduction}

Odontogenic Myxofibroma (OM) is a rare benign neoplasm characterized grossly by mucoid or grey-ish-white gelatinous tissue and is thought to be of mesenchymal or ectomesenchymal origin. ${ }^{1-6}$ These slow-growing tumors consist of an accumulation of mucoid ground substance with little collagen, the amount of which determines whether they are called myxofibromas. A myxofibroma of the bone is a rare lesion, which occurs almost exclusively in the jaws. In some cases, a myxoma is an aggressive tumor capable of extensive local infiltration and bone destruction and it can spread into adjacent soft tissues. Odontogenic myxomas are asymptomatic. Pain, paresthesia or asymmetries occur only when they take on larger sizes. The mandibular is involved more often than the maxilla and most reports show a slight predilection for females. The angle of the jaw, ramus, and adjacent molar region are most commonly affected. The anterior mandibular is involved less frequently than the posterior mandibular and ramus. Myxomas usually occur in the 2nd and 4th decades of life, with a peak in the 3 rd decade. ${ }^{7-14}$

Radiographically, the tumor presents as a unilocular or multilocular radiolucent lesion with well-defined borders with fine bony trabeculae within its interior structure expressing a "honeycombed", "soap bubble" or "tennis racket" appearance. Unilocular appearance may be seen more commonly in children and in the anterior parts of jaws. Displacement of teeth is a relatively common finding, root resorption is rarely seen and the tumor is often scalloped between roots. ${ }^{9,15-18}$

A histological characteristic of this tumor resembles the mesenchymal portion of a tooth in development. OM consists of rounded, spindled, fusiforms and star cells arranged in a loose, abundant myxoid stroma with few collagen fibrils. Small islands of apparently inactive epithelial odontogenic rests may be scattered through the myxoid substance without any capsule, ${ }^{9,15}$

Management vary from conservative approaches, such as curettage or enucleation, to more aggressive lesions requiring en bloc resection. ${ }^{7,8,15}$ Because of its high rate of recurrence, especially due to its gelatinous and mucous aspect and having no capsule, surgical treatment through bone resection is the most indicated treatment modality, followed by long-term follow up. ${ }^{9}$

In this article, we present a case of hemimandibulectomy of large OM occurring in the mandibular of a 15 year old girl patient followed by immediate $\mathrm{AO}$ plate reconstruction and review of the literature. 

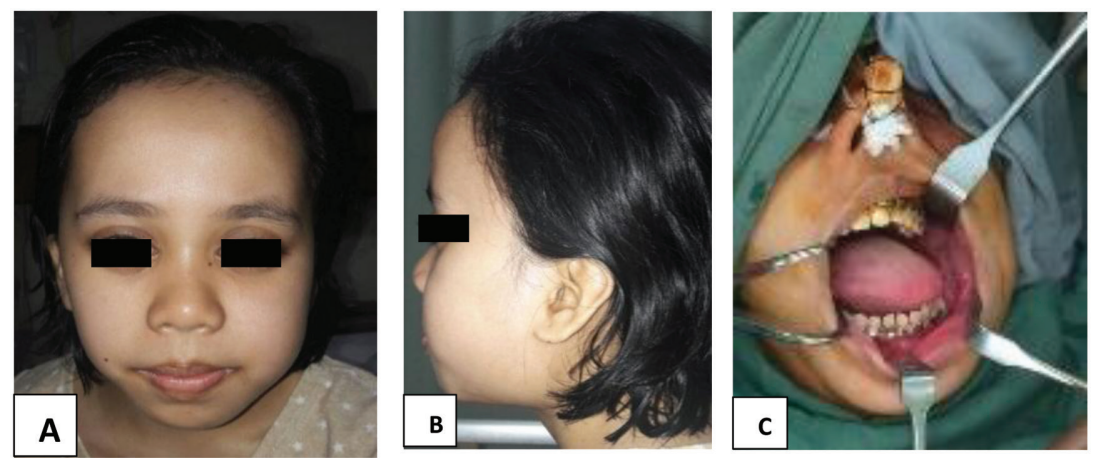

Figure 1 A. Mild facial asymmetry on the left side. B. Swelling on left side of the mandibular body and ramus region C. An ovoid, firm to hard non-tender swelling with diffuse borders and smooth surface extended medially with lifting base of the tongue

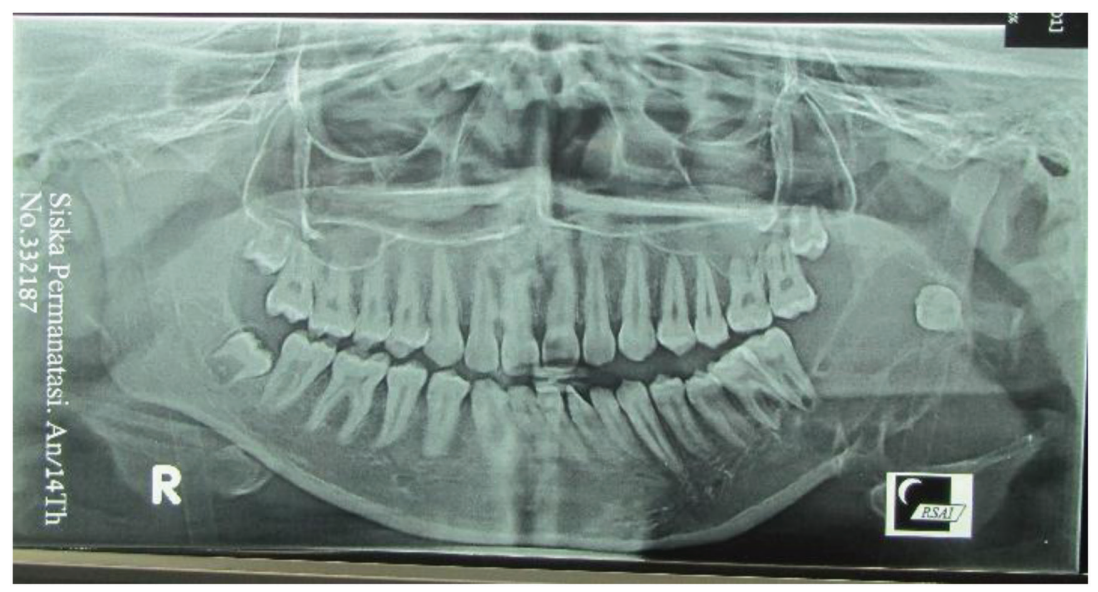

Figure 2 Panoramic radiograph revealed large multilocular radiolucency extending from first molar up to coronoid process with impacted 3rd molar
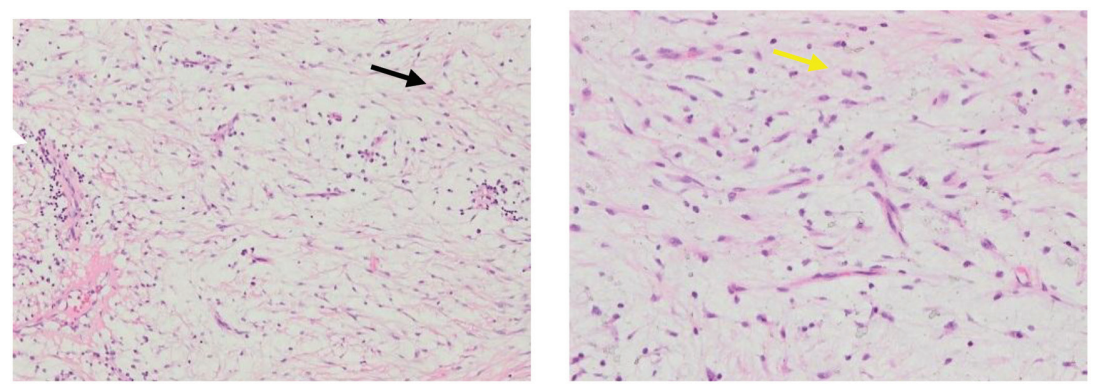

Figure 3 Histolopathologic images: H\&E stained sections 100X (A), 200X (B) showing spindle shaped cells (yellow arrow) in loose myxoid stroma with delicate fibrils (black arrow), dense collagen fibers, and odontogenic rests (white arrow)

\section{Case Report}

A 15 year old girl patient reported to the Department of Oral \& Maxillofacial Surgery Hasan Sadikin General Hospital, Bandung with the chief complaint of swelling on left mandibular region since 3 years. Swelling had gradually increased to attain the present size and was completely asymptomatic. She gave history of extraction of lower left tooth because of mobility 1 years back.

Extra-oral examination revealed an ovoid, hard swelling in the left posterior mandibular, extending to the ramus causing mild facial asymmetry. The swelling had a smooth surface and indistinct borders. Intra-oral examination revealed an ovoid, firm to hard non-tender swellingwith diffuse borders and smooth surface extended medially with lifting base of the tongue figure 1 .

The vestibular space was obliterated and mandibular left second molars were missing. The regional lymph nodes were not palpable. Provisional diagnosis of a benign odontogenic tumour of left mandibular region was given.

Patient was advised panoramic radiograph and the result revealed large multilocular radiolucency extending from first molar up to coronoid process with impacted 3 rd molar. It also showed fine, lacy trabeculation as well as angular septae at various sites giving rise to different geometric forms and largely a soap bubble appearance. Figure 2 At this point, clinical and radiographic features were suggestive of a locally invasive benign odontogenic tumour. Differential diagnosis or the same included ameloblastoma odontogenic myxofibroma and keratocystic odontogenic tumor.

To investigate further, incisional biopsy of the lesion was done, followed by histopathological evaluation. Based on histopathological features a final diagnosis of odontogenic myxofibroma was made. Figure 3 Management for odontogenic myxofibroma depends upon the extension of the lesion. However, considering the non capsulated nature of the tumour, tendency to infiltrate locally, extent of the lesion and mandibular cortex damage, aggressive hemimandibulectomy with immediate AO plate reconstruction was decided.

Under general anesthesia, the patient underwent excision of the lesion along with hemimandibulectomy with immediate reconstruction of mandibular with AO plate. A submandibular incision pararel with inferior border of mandibular and vestibular incision intra orally along the lesion was used as an approach. An AO plate was contoured and fit to the mandibular border to have appropriate facial projection. Osteotomies were accomplished with a reciprocating saw at distal first premolar margins. No curettage was necessary as the specimen included the entire tumour. The wire maxillomandibular fixation (MOM) was installed to maintain occlusion. The patient left the hospital on the fourth post operative day and the rubber MOM was maintain for 2 months. The patient will be followed up closely for 2 years figure 4 . 


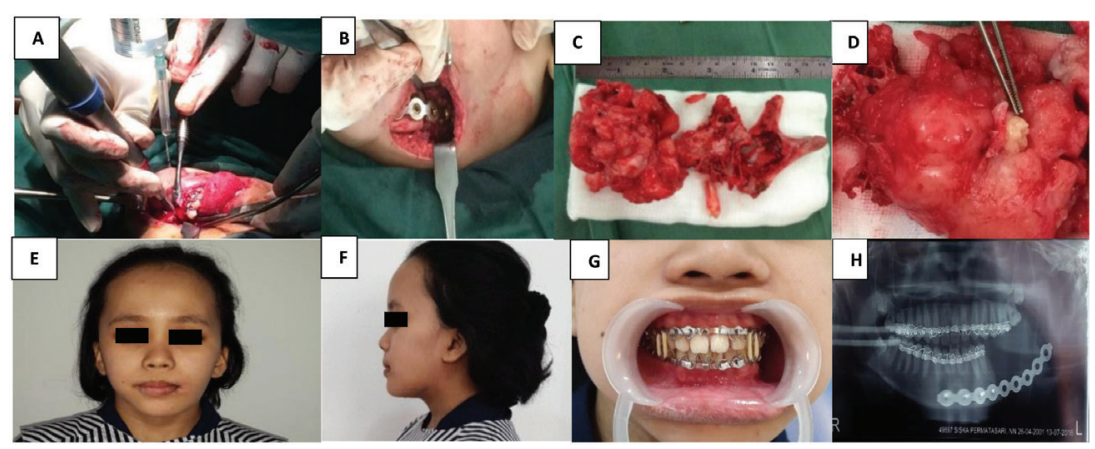

Figure 4 Mandibular osteotomy transoral B. AO reconstruction plate in situ after hemimandibulectomy C. Resection specimen with large mass D. 3rd molar inside the mass E and F. Postoperative facial appearance G. Postoperative occlusion. H. Postoperative panoramic radiograph

\section{Discussion}

OM are benign but locally aggressive odontogenic tumors which affect almost exclusively the jaws. The mandibular is more frequently affected than the maxilla with a predilection for the posterior region in the both jaws. ${ }^{1,8}$ Most of the cases reported were diagnosed between the second and fourth decades of life with a peak in the third decade. The majority of OM are asymptomatic, even though few patients were reported to have increasing pain associated to invasion of surrounding structures. Apparently, patients with posteriorly located tumors had a late diagnosis and bigger lesions when compared to those with anteriorly located tumors. This is probably due to more visible disfigurement when the lesions are located in the anterior area. ${ }^{1,8,16}$

Radiological examination plays a crucial role for the differential diagnosis of OM, which includes other pathological conditions like: odontogenic fibroma, fibrous dysplasia, ameloblastoma, keratocyst odontogenic tumor, central giant cell granuloma. ${ }^{8}$ Similarly to other odontogenic tumors, terms such as "soap bubbles", "ground glass" or "tennis racquet appearance" have all been used to describe the radiographic appearances of these lesions. ${ }^{1}$ The tennis racket appearance where the bony septae appear as triangular, square or rectangular compartments with very fine trabeculation within them is the most common. ${ }^{9,15,16}$

The gross appearance of the surgical specimen which displayed a hard-fibrous consistence, could lead the surgeons toward the hypothesis of a myxomatous lesion. As for the other odontogenic tumors, definitive diagnosis of $\mathrm{OM}$ is based on histopathologic evaluation. ${ }^{1}$ In case of big lesions, a biopsy may be necessary to establish the nature of the tumor and to plan the therapeutic approach. Histopathologically odontogenic myxomas are characterized by embedding of stellate and spindle-shaped cells in a richly myxoid extracellular matrix. Collagen is usually present scarcely, however higher amounts of collagen may be present in some cases. ${ }^{16,18}$

Surgical excision has been reported as the treatment of choice. No agreement exists on the extension of surgical margins. Radical treatment (e.g. en bloc resection) is suggested by some surgeons on the basis of characteristics of OM such as the locally aggressive nature, the possible large size and tendency to recur. Recurrence is probably associated to local invasion into cancellous bone beyond radiographically visible margins in absence of tumor encapsulation. Recurrence rate can apparently be reduced with a more aggressive treatment by performing a partial or complete segmental bone resection with tumor free margins of $1.5 \mathrm{~cm}$. The patient should be monitored for at least three years after the surgical intervention as the recurrence rate seems to be higher during this period. .14,18 $^{1,18}$

The AO reconstruction plate has been used in mandibular reconstruction since the late 1970s. Komisar, et al reported their experience with AO plating for mandibular reconstruction and they were strong proponents of this form of reconstruction because of the ease in applying the prosthesis, the low perioperative morbidityrate, the excellent cosmetic results, and the possibility of rapid rehabilitation of mastication and deglutition. ${ }^{19}$

\section{Conclusion}

$\mathrm{OM}$ has variable radiographic findings, but fine trabeculations forming at left angle are highly suggestive of odontogenic myxofibroma. A biopsy is required to confirm the diagnosis. A radical surgical approach is recommended for OM because of their higher reported recurrence rate. In addition, a long term follow-up is needed.

\section{Conflict of Interest}

The authors report no conflict of interest.

\section{References}

1. Meleti M, Giovannacci I, Corradi D, et al. Odontogenic myxofibroma: A concise review of the literature with emphasis on the surgical approach. Med Oral Patol Oral Cir Bucal. 2015;20 (1):1-6.

2. Sriram K, Lavanya S, Ramesh V, Premalatha B. Odontogenic myxofibroma with abundant calcifications, masquerading as a fibro-osseous lesion: A diagnostic dilemma. Indian J Oral Sci 2012;3:99-102.

3. Jiang $\mathrm{C}, \mathrm{Xu}$ Q, Zhang Q, Carrasco LR, Le AD. Benign Odontogenic Tumors: Origins, Immunophenotypic Features, and Genetic Alterations. Curr Oral Health Rep 2016; 3:93-101. 
4. Manjunath SM, Gupta AA, Swetha P, Moon NJ, Singh S, Singh A. Report of a rare case of an odontogenic myxoma of the maxilla and review of literature. Ann Med Health Sci Res 2014;4: 45-8.

5. Toro MDC, Barreto IS, Amstalden EMI, et al. Odontogenic myxoma in children: a case report and literature review. Case reports in oncological Med 2016; 1-6.

6. Hasan S, Jain S. Odontogenic Myxoma of the Mandibular: case report and literature review. Int J Oral-Med Sci 2012;11: 120-125,.

7. Cankaya $A B$, et al. Myxofibroma of the maxilla, current concepts and differential diagnosis. J Dent Sci 2013; 1-4.

8. Rius JM, Nadal A, Lahor E, et al. Unusual presentation of localized gingival enlargement associated with a slow-growing odontogenic myxoma. International J Oral Sci 2013;5: 172-175.

9. Limdiwala P, Shah J. Odontogenic myxoma of maxilla: a review discussion with two case reports. Contemp Clin Dent 2015;6: 131-136.

10. Fometea B, Adebayob ET, Agbaraa R, et al. Massive peripheral odontogenic myxoma in a child: case report and review of literature. J Oral \& Maxillofac Surg, Med \& Pathol 2014;26: 163-165.

11. Kansy K. Odontogenic myxoma: diagnostic and therapeutic challenges in paediatric and adult patients: a case series and review of the literature. J Cranio Maxillofac Surg 2012;40: 271-276.

12. Dunphy L, Shah S, Halsnad M, et al. Odontogenic myxoma presenting as a spontaneous oro-nasal fistula: a case report. Oral Surg 2014; 1-4.
13. Reddy GP, Badam RK, Vaddeswarapu RM, et al. Aggressive fibromyxoma of the maxilla. J Cranio Max Dis 2013;2: 170-174.

14. Nguyen S, Charbonneau SP, Ghannoum JE, et al. Extensive odontogenic myxoma of the maxilla: a case report and review of literature. Int J Otolaryngol, Head \& Neck Surg 2014;3: 364-370.

15. Friedrich. Radiographic findings in odontogenic myxoma. Anti Cancer Res 2012;32: 2173-2178.

16. Aditya A, Khandelwal P, Joshi S, et al. Odontogenic myxoma of mandibular: report of a rare case. J Clinical \& Diagnostic Res 2016;10: ZJ01-ZJ02.

17. Kheir E, Stephen L, Nortje C, et al. The imaging characteristics of odontogenic myxoma and a comparison of three different imaging modalities. Oral \& Maxillof Radiol 2013;116: 492-502.

18. Chavan S, Prabhune S, Pawar R, et al. Odontogenic myxomas with an unusual presentation in the anterior mandibular: a case report. Indian J Medno dent Allied Sci 2014;2: 115-118.

19. Komisar A, Danziger E, Shapiro B, et al. The use of osteosynthesis in immediate and delayed mandibular reconstruction. Laryngoscope 1985;95: 1363-1366.

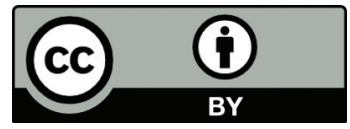

This work is licensed under a Creative Commons Attribution 